\title{
TEORIA E PRÁTICA NA FORMACִÃO DE PROFESSORES: A PRÁTICA COMO TECNOLOGIA DO EU DOCENTE'
}

\author{
Maria Manuela Alves Garcia* \\ Márcia Souza da Fonseca** \\ Vanessa Caldeira Leite ${ }^{* *}$
}

RESUMO: Este artigo discute a relação teoria e prática nas Diretrizes Curriculares Nacionais para a Formação dos Professores da Educação Básica, no início da década de 2000. Tem como fonte de dados a legislação curricular que instituiu a reforma e os Projetos Pedagógicos de quatro cursos de licenciatura da Universidade Federal de Pelotas (Educação Física, Artes Visuais, Matemática e Ciências Sociais). A partir dos estudos de Michel Foucault sobre a governamentalidade e a ética e de estudos sobre as políticas educacionais e curriculares contemporâneas, mostra os efeitos da nova matriz curricular nos currículos dos cursos investigados. O estudo demonstra que a política oficial reforça o pragmatismo na educação de professores e problematiza a prática como tecnologia do eu docente implicada na formação de um professor prático-reflexivo, em uma visão reducionista das competências e habilidades docentes.

Palavras-chave: Currículo; Formação de Professores; Teoria e Prática.

\footnotetext{
* Doutora em Educação pela Universidade Federal do Rio Grande do Sul (UFRGS); Professora do Programa de Pós-Graduação em Educação da Universidade Federal de Pelotas (UFPel). E-mail: garciamariamanuela@gmail.com

* * Doutora em Educação pela Pontifícia Universidade Católica do Rio Grande do Sul (PUCRS); Professora do Instituto de Física e Matemática e do Programa de Pós-Graduação em Ensino de Ciências e Matemática da Universidade Federal de Pelotas (UFPel). E-mail: mszfonseca@gmail.com

*** Doutoranda em Educação pelo Programa de Pós-Graduação em Educação Universidade Federal de Pelotas (UFPel); Professora Assistente do Curso de Teatro da Universidade Federal de Pelotas (UFPel). E-mail: leite.vanessa@hotmail.com
} 
THEORY AND PRACTICE IN TEACHER TRAINING:

PRACTICE AS TECHNOLOGY FOR THE SELF-TEACHER

ABSTRACT: This work approaches the relation between theory and practice in the scope of the Diretrizes Curriculares Nacionais (national syllabus guidelines) for the Basic Education Teacher Training, in the early 2000s. It uses as source the syllabus guidelines that instituted the Reform and Educational Projects of four undergraduate courses of the Federal University of Pelotas (Physical Education, Visual Arts, Mathematics and Social Science). From the study of Michel Foucault concerning governmentality and ethics, and from studies on education and contemporary syllabus policies, this paper shows the effects of the new curriculum design in the investigated courses. It also shows that official policy reinforces pragmatism in teacher education and problematizes the practice as the self-teacher technology involved in the formation of a practical-reflective teacher, from a reductionist view of skills and teaching abilities.

Keywords: Syllabus; Teacher Training; Theory and Practice.

A relação teoria e prática na legislação curricular oficial para a formação inicial de professores e para o trabalho docente na Educação Básica pouco tem sido objeto de reflexão sistemática no campo educacional e curricular. ${ }^{2}$

As instâncias da prática de ensino e/ou da experiência docente têm um lugar já assegurado nos processos de profissionalização e construção da competência profissional dos docentes, seja pela tradição, ou pela literatura sobre trabalho e profissão docente em anos recentes A exaltação das virtudes da prática e dos saberes da experiência no campo da pedagogia e da formação de professores é um desses axiomas do qual poucos duvidam, sejam professores ou ainda aprendizes de professor, pesquisadores e intelectuais do campo educacional. Problematizar essa questão é o que aqui se tenta fazer, como resultado da preocupação com os efeitos que esses discursos vêm produzindo nos currículos de formação de professores e na identidade docente para a Educação Básica.

Pretende-se demonstrar que as políticas oficiais para a formação inicial dos professores vêm instituindo uma forma de profissionalismo docente que tem no pragmatismo um dos seus pilares fundamentais. Percorrendo o discurso da legislação sobre a matriz curricular que pautou a reforma dos cursos e analisando os movimentos dos saberes que 
deixaram de compor ou vieram a compor os currículos reformados aqui analisados, apontam-se alguns indícios do que antes foi defendido.

Adotam-se como fonte de dados alguns documentos que instituíram as Diretrizes Curriculares Nacionais para a Formação de Professores da Educação Básica, em nível superior, cursos de licenciatura, de graduação plena (Parecer CNE/CP 9/2001, de 08.05.2001; Resolução CNE/CP 1/2002, de 18.02.2002 e Resolução CNE/CP 2/2002, de 19.02.2002, Parecer CNE CP/21, de 06/08/2001 - Não homologado, Parecer CNE/CP 28/2001, de 02.10.2001) e, ainda, os Projetos Políticos Pedagógicos e os currículos de quatro cursos de licenciatura da Universidade Federal de Pelotas (Licenciatura em Educação Física, Licenciatura em Ciências Sociais, Licenciatura em Artes Visuais e Licenciatura em Matemática). Esses cursos foram escolhidos por representarem as áreas de conhecimento em que se distribuíam os cursos de licenciatura da UFPel: Ciências Biológicas, Ciências Humanas, Letras e Artes, Ciências Exatas e Tecnologia. Nesses documentos, procurou-se analisar como foram definidos os saberes da formação inicial dos docentes, especialmente a relação teoria e prática, considerando os textos da legislação curricular e os projetos pedagógicos e currículos escritos dos cursos investigados, incluindo a análise de documentos, como planos de curso.

Através dos estudos de Michel Foucault acerca do discurso, da governamentalidade e da ética, e de outros estudos do campo das políticas educacionais e do currículo, pretende-se problematizar o caráter contraditório e pragmatista das indicações oficiais para a formação inicial de professores e para o trabalho docente, discutindo a prática como tecnologia do eu docente nos cursos de licenciatura. Evidencia-se o compromisso dessa tecnologia, no discurso da política oficial para a formação dos docentes da Educação Básica, com a formação de um professor prático-reflexivo, em uma visão reducionista das competências e habilidades docentes. 


\section{A problemática da pesquisa e seus referenciais analíticos}

A problemática deste estudo é em grande parte influenciada pelos estudos de Foucault (1990a, b, c, 1995) acerca dos discursos, da governamentalidade e dos modos de subjetivação, ou da ética. Trabalhase com a ideia de que as reformas e as políticas curriculares são parte de uma racionalidade ou sistema de razão que busca certos reordenamentos da vida social, cultural, política, econômica, etc. Nesse processo, a pedagogia e os currículos potencializam um conjunto de pensamentos e ações dos indivíduos, envolvendo-os em trabalho ético em que se tomam a si mesmos como objetos de formação e transformação (LARROSA, 1994; GARCIA, 2009) no interior de determinadas práticas e saberes curriculares.

Também as observações aqui feitas são estimuladas pelos estudos de Ball (1994) acerca da elaboração e da construção das políticas curriculares, possibilitando o diálogo e o confronto da legislação curricular oficial com as condições de possibilidade de sua leitura e recontextualização em contextos particulares. Nesse sentido, é ilustrativo o movimento nos saberes da formação profissional dos docentes em currículos de licenciatura da UFPel, desde a instituição da reforma no princípio desta década. A política, entendida como texto e como discurso, envolve os processos sociais, políticos, culturais de sua elaboração e recontextualização em diferentes instâncias do sistema educacional, bem como os seus resultados.

Como texto, as políticas são representações codificadas e decodificadas de modos complexos. Os textos das políticas são o resultado de compromissos variados, de relações de força entre diferentes posições, o que os torna, por vezes, obscuros, omissos, incompletos e abertos à significação. Os textos das políticas definem a substância dos conflitos, identificam os lugares que devem ser ocupados pelos agentes escolares, distribuem e redistribuem as relações de poder, mas, por outro lado, são constantemente trabalhados e alterados em diferentes arenas da política. Suas propostas e intenções são reorientadas no confronto com as mentalidades dos agentes educacionais e escolares e com problemas materiais, como os recursos financeiros e humanos disponíveis, a política das instituições, a força da tradição, etc. $\mathrm{O}$ conceito de recontextualização, desenvolvido por Bernstein, B. (1998), é apropriado 
para nomear esses processos de ressignificação implicados na construção das políticas curriculares.

Ainda sobre as relações entre os textos da política e os contextos da prática, diz Ball (1994) que os textos não falam claramente o que deve ser feito, mas criam circunstâncias nas quais é possível decidir entre um leque de opções possíveis. As políticas transformam algumas das condições sob as quais se trabalha, mas não modificam todas as circunstâncias. As políticas são ações sociais criativas e o resultado de conflitos entre interesses no contexto, não podendo ser lidas a partir exclusivamente dos textos.

Como discurso, a política curricular conecta necessidades de gestão e administração da população com as aspirações e expectativas individuais e está implicada em uma política de verdade e conhecimento na sociedade. O discurso tem conexões profundas com o desejo e o poder e tem efeitos de verdade, pois são "práticas que formam sistematicamente os objetos de que tratam” (FOUCAULT, 1995). As políticas são sistemas de práticas e um conjunto de éticas e valores implicados na produção de certas formas de sociabilidade, subjetividade e trabalho.

A política curricular é um dispositivo de governamentalidade (FOUCAULT, 1990b), instituindo significados acerca da formação humana e racionalidades que fabricam formas de subjetividade e relações sociais. As políticas curriculares e as reformas são dispositivos de regulação social que vinculam objetivos administrativos do Estado à liberdade dos sujeitos, e suas implicações fundamentais estão no modo como os sujeitos são levados a construírem suas experiências subjetivas e a posicionarem-se nas relações sociais (POPKEWITZ, 1997; BALL, 2005).

Desse modo, o que está em jogo com as novas diretrizes para a formação dos professores e a organização do trabalho docente na Educação Básica é centralmente a formação de outro modelo de professor. Privilegiando e excluindo saberes do processo de profissionalização; distribuindo-os em séries temporais ao longo da duração do curso do aluno; estabelecendo competências, atribuições e responsabilidades para o trabalho docente e os processos de formação profissional; instituindo distinções e visões acerca do ensino e da aprendizagem, o currículo consagra uma determinada política de espacialização e temporalização do conhecimento, atravessada por relações de poder-saber (FOUCAULT, 
1990a), que capacitam os sujeitos diferentemente para a ação e a participação no mundo.

Diante disso, deseja-se, neste artigo, problematizar essas questões no campo aqui delimitado pela reforma dos cursos de licenciatura e a profissionalização inicial dos docentes em nível superior. Para tanto, percorrem-se, primeiramente, os enunciados dos textos curriculares prescritos a partir das instâncias oficiais, identificando suas proposições e relacionando-as de modo a individualizar alguns de seus enunciados e paradigmas para a organização dos saberes curriculares da formação profissional e da relação teoria e prática; em segundo lugar, apresenta-se um conjunto de gráficos e observações que mapeiam os processos de exclusão e inclusão de saberes e componentes curriculares, como resultado da incorporação pelos currículos dos cursos investigados da legislação oficial. Por último, finaliza-se com algumas considerações de ordem conceitual a fim de potencializar novos pensamentos no campo da formação e da identidade profissional dos docentes da Educação Básica.

\section{A relação teoria e prática nas normativas oficiais para a formação inicial dos docentes em cursos de licenciatura}

Fazendo a crítica aos problemas que têm pautado a formação inicial de professores em nível superior, o Parecer CNE/CP 9/2001, que lança os fundamentos da reforma e justifica a Resolução CNE/CP $1 / 2002$, que, efetivamente, institui a reforma, denuncia a dominância nos currículos de uma concepção da relação teoria e prática que segmenta os cursos de licenciatura em dois polos isolados entre si. O primeiro, centrado nos conhecimentos teóricos e acadêmicos que caracterizam o trabalho na sala de aula, "desprezando as práticas como importante fonte de conteúdos da formação". O segundo, pautado por uma "visão aplicacionista das teorias", que "supervaloriza o fazer pedagógico, desprezando a dimensão teórica" como essencial para a seleção e a análise das práticas, redundando em uma "visão ativista da prática", que culmina com os estágios ao final do curso (BRASIL, 2001a, p.22-23).

Para superar esse problema, o Parecer propõe a relação teoria e prática enquanto um princípio metodológico geral no qual “todo fazer 
implica reflexão e toda a reflexão implica um fazer, ainda que nem sempre este se materialize" (BRASIL, 2001a, p.56). Indica também que a prática, na matriz curricular dos cursos de formação, não fique reduzida "ao estágio como algo fechado em si mesmo e desarticulado do restante do curso" (BRASIL, 2001a, p.57). Acrescenta que: "Esse princípio é operacional e sua aplicação não exige uma resposta definitiva sobre qual dimensão - a teoria ou a prática - deve ter prioridade, muito menos qual delas deva ser o ponto de partida na formação do professor" (BRASIL, 2001a, p.56).

Conforme essa legislação, a articulação entre teoria e prática deve-se dar em diferentes tempos e espaços curriculares, o que pode acontecer: 1) em situações didáticas de qualquer disciplina; 2) em tempos e espaços curriculares específicos que devem preocupar-se em fazer uma coordenação da dimensão prática em uma perspectiva interdisciplinar e com o auxílio de todos os professores formadores, com ênfase nos procedimentos de observação e reflexão da "prática direta" ou indireta, e na solução de problemas; 3) nos estágios nas escolas de Educação Básica, que devem acontecer ao longo do curso (BRASIL, 2001a, p.57-58), com a participação das instituições escolares e dos professores em tarefas definidas por um processo de planejamento e avaliação conjuntos (BRASIL, 2001a).

Nesse documento, há uma tendência a entender a relação teoria e prática tanto enquanto um princípio metodológico geral, que deve pautar todas as experiências de conhecimento do currículo, sejam elas reunidas sob o nome de disciplinas ou não, como enquanto um componente do currículo com território de saber e fazer próprios, além da prática de ensino ou da realização do estágio obrigatório:

Uma concepção de prática mais como componente curricular implica vê-la como uma dimensão do conhecimento que tanto está presente nos cursos de formação, nos momentos em que se trabalha na reflexão sobre a atividade profissional, como durante o estágio, nos momentos em que se exercita a atividade profissional.

O planejamento e a execução das práticas no estágio devem estar apoiados nas reflexões desenvolvidas nos cursos de formação. A avaliação da prática, por outro lado, constitui momento privilegiado para uma visão crítica da teoria e da estrutura curricular do curso. Trata-se, assim, de tarefa para toda a equipe de formadores, e não, apenas, para o "supervisor de estágio" (BRASIL, 2001a, p.23). 
E, logo mais adiante, o documento conclui: "A ideia a ser superada, enfim, é a de que o estágio é o espaço reservado à prática, enquanto, na sala de aula, se dá conta da teoria" (BRASIL, 2001a, p.23).

Para dar materialidade a essas indicações, a Resolução $\mathrm{CNE} / \mathrm{CP} 2 / 2002$, que institui a matriz curricular dos cursos de licenciatura, alocou 800 horas a serem distribuídas equitativamente entre o que denomina de "Prática como Componente Curricular" e "Estágio Supervisionado", e 1800 horas previstas para "conteúdos curriculares de natureza científico-cultural, dedicadas às atividades de ensino e aprendizagem", acrescidas de 200 horas de "outras formas de atividades acadêmico-científico-culturais, que incluem atividades de enriquecimento didático, curricular e científico e cultural, como monitorias, participação em pesquisas, eventos científicos, etc." (BRASIL, 2002b).

$\mathrm{Na}$ medida em que define a prática como componente curricular com tempo próprio entre os saberes da formação profissional, subsumindo o princípio metodológico da indissociabilidade que deveria perpassar todas as experiências de conhecimento e disciplinas no currículo, a medida oficial termina por reforçar a dicotomia entre teoria e prática na formação inicial dos docentes. A leitura dessa normativa pelos filtros de um forte pragmatismo que historicamente tem caracterizado a pedagogia e o ensino, e de uma tradição curricular disciplinar que espacializa em tempos e lugares distintos a teoria e a prática, reinscreveu essa separação nos currículos da maioria das licenciaturas analisadas na UFPel e implicou a interpretação desse componente como uma disciplina que deveria compor os currículos de licenciatura.

É interessante observar como o Parecer CNE/CP 28, de 02 de outubro de 2001, justifica e explica os diferentes componentes curriculares propostos pela Resolução CNE/CP 2/2002. A prática como componente curricular

[...] é, pois, uma prática que produz algo no âmbito do ensino. Sendo a prática um trabalho consciente cujas diretrizes se nutrem do Parecer 9/01, ela terá que ser uma atividade tão flexível quanto outros pontos de apoio do processo formativo, a fim de dar conta dos múltiplos modos de ser da atividade acadêmico-científica.

Assim, ela deve ser planejada quando da elaboração do projeto pedagógico e seu acontecer deve-se dar desde o início da duração do processo formativo e se estender ao longo de todo o seu processo. Em articulação intrínseca com o estágio supervisionado e com as atividades de trabalho acadêmi- 
co, ela concorre conjuntamente para a formação da identidade do professor como educador (BRASIL, 2001c, p.9).

E continua dizendo:

Esta correlação teoria e prática é um movimento contínuo entre saber e fazer na busca de significados na gestão, administração e resolução de situações próprias do ambiente da educação escolar.

A prática, como componente curricular, que terá necessariamente a marca dos projetos pedagógicos das instituições formadoras, ao transcender a sala de aula para o conjunto do ambiente escolar e da própria educação escolar, pode envolver uma articulação com os órgãos normativos e com os órgãos executivos dos sistemas (Brasil, 2001c, p.9).

Há um aspecto da elaboração do texto desse Parecer que precisa ser destacado nesta discussão. Houve uma primeira formulação não homologada desse Parecer - Parecer CNE/CP 21/2001, não homologado - que, ao invés de utilizar a expressão "prática como componente curricular", utilizava "prática de ensino", definindo-a exatamente como já apresentado. A versão do Parecer homologado (Parecer CNE/CP 28, de 02 de outubro de 2001), ao retirar o "de ensino", possibilitou a inclusão de práticas que não as estritamente relacionadas à instrumentalização para a docência e o ensino escolar, deixando para os cursos a decisão sobre essa matéria. Podem-se supor, por essa mudança de termos, os embates que envolveram o processo de significação dessa questão na formação inicial dos professores.

Se se compararem as caracterizações dos Pareceres CNE/CP 9/2001 e CNE/CP 28/2001 em relação à prática como componente curricular, observa-se que a ideia inicial desse componente da formação como o lugar no currículo de coordenação da dimensão prática (BRASIL, 2001a, p.57-58) que envolveria todos os professores formadores do curso em um trabalho de tipo interdisciplinar, é abandonada no Parecer CNE/CP 28/2001. Levando em conta a estrutura administrativa e acadêmica das universidades e da maioria das instituições formadoras de nível superior, há que se considerar o idealismo da formulação oficial naquele Parecer e seu distanciamento das condições objetivas de trabalho das instituições formadoras, que lutam contra a intensificação e a precarização do trabalho frente ao crescimento exponencial dos cursos e dos estudantes de ensino superior na rede federal. 
Por sua vez, o estágio curricular supervisionado é definido

[...] como o tempo de aprendizagem que, através de um período de permanência, alguém se demora em algum lugar ou ofício para aprender a prática do mesmo e depois poder exercer uma profissão ou ofício, supondo uma relação pedagógica entre alguém que já é um profissional reconhecido em um ambiente institucional de trabalho e um aluno estagiário. Por isso é que esse momento se chama estágio supervisionado (BRASIL, 2001c, p.10).

Mais adiante, destaca que a realização do estágio é efetiva condição para a obtenção da licença e que se caracteriza pelo "exercício direto in loco, pela presença participativa em ambientes próprios de atividades daquela área profissional, sob a responsabilidade de um profissional já habilitado" (BRASIL, 2001c, p.10).

Ao definir a vocação da presença na matriz curricular do estágio supervisionado e suas contribuições na formação profissional, destaca três aspectos: oferece ao aluno o conhecimento do real em situação de trabalho; possibilita a verificação em si e no outro das competências exigidas na prática profissional e, por último, permite o conhecimento das rotinas da vida da escola, especialmente das que não acontecem todos os dias (matrículas, organização de turmas, elaboração de projeto pedagógico, etc.). Veja-se que a prática aparece nessas definições como a possibilidade de conhecer o real da escola e do ensino e como lugar de testar o que se aprendeu no curso durante a formação e provar suas competências (BRASIL, 2001c, p.10).

O Parecer CNE/CP 28/2001 enfatiza que a prática como componente curricular e o estágio são componentes curriculares "próprios do momento do fazer", oportunidades de desenvolver trabalho acadêmico sob o princípio da ação-reflexão-ação, cuja estratégia didática deve ser preferentemente a solução de problemas e o desenvolvimento de projetos, conforme indica o Parecer CNE/CP 9/2001 (BRASIL, 2001a, c).

O Parecer propõe também um componente do trabalho acadêmico que caracteriza como "o ensino que se desenvolve em aula", de caráter presencial, estabelecido em um total de 1800 horas. Completando esse componente do trabalho acadêmico, indica, adicionalmente, o cumprimento de 200 horas de atividades de caráter científico, cultural e acadêmico, à escolha do aluno e orientadas por um professor. Essas atividades incluem participação em seminários, em pesquisas, 
cursos de extensão, apresentação de trabalhos em eventos, etc. e têm o objetivo de atender ao princípio de uma flexibilização curricular que contemple as escolhas dos alunos (BRASIL, 2001c, p.12-13).

Foram assim estabelecidos os componentes da matriz curricular, segundo palavras do documento oficial, "conhecimentos e experiências", para compor "um saber profissional, crítico e competente" que deve caracterizar o ser do professor, visando a contemplar a exigência de profissionalização com um "alto teor de excelência formativa" e voltada aos objetivos da Educação Básica (BRASIL, 2001c, p.12).

Como se pode observar, a legislação, na intenção de conferir um estatuto diferenciado à prática e à experiência na formação inicial dos docentes e na construção de sua competência profissional, estabelece e reforça polarizações que pretendia redimir. Teoria e prática, conhecimento e experiência, aula e fazer terminam por ser dicotomizados e alocados em territórios fixos, claramente delimitados no tempo de duração e na distribuição da carga horária entre os diferentes componentes curriculares dos cursos.

Vários estudos (DUARTE, 2003; LOUREIRO, 2007; DIAS; LOPES, 2009) têm apontado o quanto a proposta curricular oficial para a formação inicial dos professores da Educação Básica vem fundamentada no que se tem chamado de uma epistemologia da prática docente. Desde esse ponto de vista, os fundamentos da competência profissional dos docentes estão em grande parte no conhecimento que advém da experiência, ou no desenvolvimento de um conhecimento tácito que só o exercício da docência e a experiência profissional possibilitam. As ideias e os estudos de Tardif (2002), Schön (1997, 2000), Perrenoud (1993), Nóvoa (1997), Zeichner (1993, 1997), etc., que vêm conquistando adeptos no Brasil desde a década de 1990, alçaram o conhecimento advindo da experiência a um campo de saber com autonomia no desenvolvimento profissional dos docentes. ${ }^{3}$ A formação de um tipo de professor prático-reflexivo que tem no conhecimento advindo da experiência um dos saberes profissionais mais importantes hegemonizou a proposta oficial, instituindo ao mesmo tempo a desvalorização dos saberes acadêmicos e disciplinares nos currículos dos cursos de licenciatura.

Como enfatiza o Parecer CNE/CP 9/2001, o conhecimento advindo da experiência é um tipo de conhecimento construído "na" e "pela" experiência que não pode ser confundido com o conhecimento 
"sobre" a experiência. Sua especificidade epistemológica não é da ordem dos objetos ou fenômenos que estuda, mas defende o discurso oficial, é da ordem das formas como esse conhecimento é construído pelo sujeito. Como defende o texto oficial: "Saber - e aprender - um conceito, ou uma teoria é muito diferente de saber - e aprender - a exercer um trabalho" (BRASIL, 2001, p.49). Esse tipo de conhecimento implica sempre formas de prática, de ação, de reflexão-na-ação do sujeito aprendiz que resultam no acúmulo de um conhecimento tácito de natureza profissional, que pode ser enriquecido com conhecimentos de outras ordens.

A recontextualização da matriz curricular proposta pela Resolução CNE/CP 2/2002 pelos filtros de um forte pragmatismo que historicamente tem caracterizado a pedagogia e o ensino, e de uma tradição curricular disciplinar que espacializa em tempos e lugares distintos a teoria e a prática, reinscreveu, na maioria dos casos, essa separação nos currículos das licenciaturas analisadas na UFPel.

\section{Implicações da matriz curricular oficial nos cursos de licenciatura da UFPel}

A inclusão nos novos currículos da carga horária destinada à Prática como Componente Curricular e ao Estágio Supervisionado foi feita, segundo o que se pôde observar, à custa da exclusão de conteúdos e disciplinas relativos à área de conhecimento que será a matéria de ensino dos futuros licenciados e, ainda, em alguns casos, à custa da redução de conteúdos pedagógicos relacionados às ciências básicas da educação. Foi o que se pôde verificar na análise dos currículos escritos das quatro licenciaturas estudadas (Educação Física, Matemática, Ciências Sociais, Artes Visuais), tendo como parâmetro de comparação os currículos desses cursos, anteriores à reforma. Justificando a reforma (BRASIL, 2001a, p.21) a partir do excessivo conteudismo dos currículos de licenciatura vigentes até então, ou, por outro lado, pelo excessivo pedagogismo dos cursos que privilegiam a transposição didática dos conteúdos a serem ensinados, a nova matriz curricular, por sua vez, pecou pelo excessivo pragmatismo.

Não se pode deixar de reconhecer que um dos resultados da reforma foi o acréscimo significativo da carga horária total destinada à 
formação pedagógica do professor, quando comparados os novos currículos com o antigo modelo curricular que fornecia as duas habilitações (licenciatura e bacharelado). A exigência legal de "terminalidade e integralidade própria em relação ao bacharelado" (BRASIL, 2001a, p.6) para os cursos de licenciatura, aliada à matriz curricular proposta pelo $\mathrm{CNE}$, favoreceu a ampliação dos saberes pedagógicos nos currículos. No entanto, a política de privilégio a saberes de ordem prática e às competências leva a problematizar as transformações que vêm ocorrendo nos saberes da formação profissional e na identidade dos professores da Educação Básica. Nesse sentido, não deixa de haver coerência entre a forma de profissionalismo almejada pela legislação para os docentes "a concepção de professor como profissional do ensino que tem como principal tarefa cuidar da aprendizagem dos alunos" (BRASIL, 2001a, p.9) - e a matriz curricular proposta pela política oficial.

Pelo exame dos projetos pedagógicos e dos currículos ${ }^{4}$ dos cursos de licenciatura em Educação Física, Artes Visuais, Matemática e Ciências Sociais, da UFPel, evidenciam-se, a seguir, algumas das afirmações feitas, e é possível refinar as observações sobre as mudanças nos saberes da formação profissional dos docentes.

De modo geral, o estudo buscou mostrar como a matriz curricular proposta pela Resolução CNE/CP 2/2002 foi ressignificada pelos cursos investigados e seus efeitos nos saberes curriculares da formação docente, tanto no campo dos saberes que representam a área de conhecimento que é objeto de ensino da licenciatura, como no campo dos saberes pedagógicos. Em relação a estes, no entanto, precisava-se de uma acuidade ainda maior. As categorias a serem utilizadas deviam possibilitar a discriminação da natureza das experiências de conhecimento que foram recontextualizadas nos currículos a partir da matriz curricular oficial.

As categorias utilizadas nos gráficos a seguir, para agrupar os saberes que vieram a compor os currículos, resultam, em grande parte, de denominações utilizadas pela própria matriz curricular oficial e pelos currículos dos cursos investigados. Algumas disciplinas encontradas nos currículos foram agrupadas em tipologias de saberes já consagrados na literatura especializada sobre os saberes docentes (TARDIF, 2002; GAUTHIER, 1998; PIMENTA, 1998), como foi o caso das disciplinas relacionadas às ciências básicas da educação e à pedagogia. 
Como se pode observar, foram mantidas as denominações da PCC e do estágio como categorias separadas, conforme propostas pela legislação. Em última análise, esses componentes poderiam ser entendidos acertadamente como parte dos conhecimentos pedagógicos. No entanto, era preciso destacar e analisar os efeitos nos currículos da extensa carga horária proposta pela legislação oficial para esses componentes e sua relação proporcional com os outros tipos de saberes nos currículos. Resultou, assim, uma categorização dos saberes curriculares dos cursos investigados que é um híbrido relacionado aos objetivos deste estudo, cujas categorias serão mais bem explicitadas nos próprios gráficos, sempre que necessário.

\section{GRÁFICO 1: Distribuição da Carga Horária noCurrículo Educação Física Hab. Licenciatura. CH Total: 2.924 h/a. Ano: 2001}

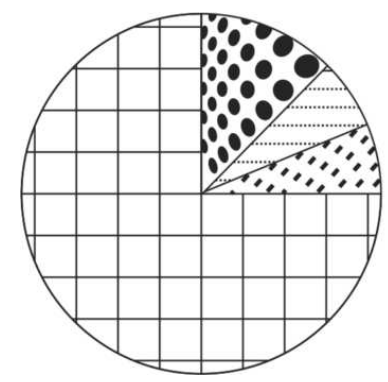

Saberes Pedagógicos e das Ciências da Educação 391 h/a* (13\%)

Estágios Supervisionados 170 h/a (6\%)

Pré-Estágios 170 h/a (6\%)

Conhecimentos Específicos da Área de Ensino 2193 h/a (75\%)

\footnotetext{
* Inclui as disciplinas: Filosofia da Educação (51 h/a); Psicologia da Educação I e II (102 h/a); Estrutura e Funcionamento do Ensino (68 h/a); Metodologia do Ensino I e II (102 h/a); Modelos e Estilos de Ensino em Educação Física (68 h/a). Fonte: UNIVERSIDADE FEDERAL DE PELOTAS/ PRÓ-REITORIA DE GRADUAÇ̃̃O/ DEPARTAMENTO DE REGISTROS ACADÊMICOS. Currículo 1 - 800 Educação Física - Lic. Plena - 2001/2. Pelotas. Impresso em 17/08/2006.
} 
GRÁFICO 2: Distribuição da Carga Horária no Currículo Educação Física - Hab. Licenciatura. CH Total: 3.555 h/a. Ano: 2009

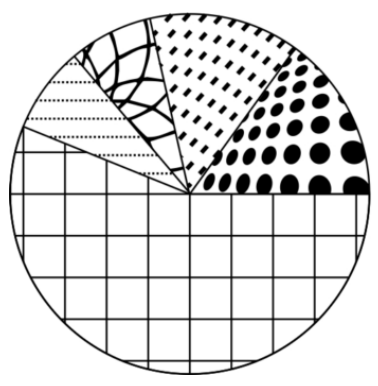

* Inclui as disciplinas: Teoria e Prática Pedagógica (68 h/a); Fundamentos Psicológicos da Educação (68 h/a); Fundamentos Sócio-Históricos-Filosóficos da Educação (68 h/a); Educação Brasileira (68 h/a); LIBRAS (68 h/a).

* * A Prática como Componente Curricular (493 h/a) no curso de Licenciatura em Educação Física inclui as disciplinas nomeadas de PCC1 a PCC5, cada qual com 68 h/a, totalizando 340 h/a, e mais 3 semestres de Práticas Pedagógicas (nas Séries Iniciais, de $5^{\mathrm{a}}$ a $8^{\mathrm{a}}$ Séries e no Ensino Médio), cada uma com 51 h/a, perfazendo $153 \mathrm{~h} / \mathrm{a}$.

Fonte: MEC/UFPel/ESEF/COLEGIADO DE CURSO. Projeto pedagógico do curso de Licenciatura em Educação Física. Pelotas, abr. 2009.

Comparando o total da carga horária do curso de Licenciatura em Educação Física (2.924 h/a), em 2001, com a carga horária total do mesmo curso ( $3.555 \mathrm{~h} / \mathrm{a})$, em 2009, observa-se um aumento de $631 \mathrm{~h} / \mathrm{a}$, ou $21,58 \%$, na última versão do currículo. Considerando que houve diminuição de 19\% na carga horária das disciplinas relacionadas aos conhecimentos específicos da área de ensino da Licenciatura (de 2.193 h/a para $1.989 \mathrm{~h} / \mathrm{a}$ ), o aumento na carga horária total foi distribuído entre os componentes de Prática como Componente Curricular (493 h/a), Estágio Supervisionado (493 h/a) e Atividades Complementares $(240 \mathrm{~h} / \mathrm{a})$.

As 170 h/a que contabilizavam para os Pré-Estágios, no currículo de 2001, passaram a compor Prática como Componente Curricular, no currículo de 2009. Assim, houve um aumento efetivo do tempo destinado aos Estágios de $223 \mathrm{~h} / \mathrm{a}$, passando de 6\% a 13,86\%. As $493 \mathrm{~h} / \mathrm{a}$ de Prática como Componente Curricular (PCC) no currículo reformado foram compostas com as atividades de Pré-Estágios do currículo de 2001, passando a se chamar PCC1 a PCC5, totalizando 340 h/a, e com três semestres de Práticas Pedagógicas (nas Séries Iniciais, de $5^{\mathrm{a}}$ a $8^{\mathrm{a}}$ Séries e no Ensino Médio), de $51 \mathrm{~h} /$ a cada uma, totalizando $153 \mathrm{~h} / \mathrm{a}$. Os Pré-Estágios eram, no currículo de 2001, e assim continuaram no currí- 
culo reformado, a oferta, por diferentes professores do curso, de atividades de ensino, pesquisa e extensão, em que os alunos participavam com o objetivo de desenvolver habilidades e competências de ordem profissional e acadêmica. Na medida em que a legislação instituiu a PCC, essas atividades passaram a compor esse componente, que, na sua totalidade, passou a representar também 14\% do tempo do currículo. Ambos os componentes passaram a ocupar $28 \%$ do total da carga horária do curso em 2009.

É interessante destacar que, de modo geral, nos casos estudados, a PCC tendeu a ser pensada enquanto um conjunto de disciplinas dedicadas, sobretudo, a atividades e práticas de caráter instrumental para o ensino e a docência. Um exemplo desse acento foi a forte migração das antigas disciplinas e conteúdos de didática e metodologias de ensino dos antigos currículos para esse componente nos currículos reformados.

A Licenciatura em Educação Física e também o curso de Licenciatura em Artes, como se verá logo a seguir, foram casos que não seguiram estritamente essa regra. A Licenciatura em Educação Física, ao reconfigurar no componente da PCC as atividades de ensino, pesquisa e extensão, que, tradicionalmente, já vinham sendo desenvolvidas na forma de pré-estágios no seu currículo antigo, também incorporou e ampliou criativamente, no currículo reformado, a instância da prática como experiência formativa, possibilitando formas de trabalho acadêmico e produção intelectual que não as estritamente relacionadas à instrumentação para a docência e o ensino na instituição escolar.

Continuando com a análise do GRÁFICO 2, o estágio supervisionado é subdividido em três semestres obrigatórios, totalizando também $493 \mathrm{~h} / \mathrm{a}$ e 14\% do total da carga horária do curso. Os dois primeiros, cada um com $170 \mathrm{~h} / \mathrm{a}$, são dedicados à regência de classe nas séries iniciais e de $5^{\mathrm{a}}$ a $8^{\mathrm{a}}$ séries, e, no terceiro semestre acontece a prática de ensino no Ensino Médio, com 153 h/a.

Também com as disciplinas do que é conhecido como "Saberes Pedagógicos e Ciências da Educação" foram feitos alguns arranjos. No currículo de 2001, essas disciplinas representavam 391 h/a, ou 13\% de um total de $2.924 \mathrm{~h} / \mathrm{a}$. Nesse conjunto, estavam incluídas as Metodologias do Ensino I e II, de 102 h/a, e Modelos e Estilos de Ensino em Educação Física, de 68 h/a, que abrangiam conteúdos do 
campo das didáticas e das práticas de ensino. Os conteúdos dessas disciplinas, totalizando $170 \mathrm{~h} / \mathrm{a}$, passaram para os semestres de PCC no currículo de 2009. As demais disciplinas que compunham esse componente no currículo de 2001, Filosofia da Educação (51 h/a) e Psicologia da Educação I e II, cada qual com 51 h/a, passaram a compor Fundamentos Sócio-Históricos-Filosóficos da Educação (68 h/a) e Fundamentos Psicológicos da Educação (68 h/a), perdendo, então, a Psicologia da Educação 34 h/a de tempo de estudo. Foi criado, ainda na versão do currículo de 2009, um semestre de Teoria e Prática Pedagógica $(68 \mathrm{~h} / \mathrm{a})$, e a antiga Estrutura e Funcionamento do Ensino $(68$ h/a) transformou-se na Educação Brasileira: Organização e Políticas Públicas $(68 \mathrm{~h} / \mathrm{a})$. Nos Saberes Pedagógicos e Ciências da Educação, no currículo de 2009, está ainda a disciplina de LIBRAS, com 68 h/a. Esse grupo tem um total de $340 \mathrm{~h} /$ a na versão do currículo de 2009 , ou $9 \%$ do total da carga horária do curso, representando um corte nesse tipo de estudos em relação ao currículo de 2001, já que, simplesmente, alguns conteúdos de ordem pedagógico-didática foram realocados nos componente da Prática como Componente Curricular. Entre os estudos pedagógicos, destaca-se a diminuição do tempo de estudo da Psicologia da Educação, mas, ao mesmo tempo, cria-se a Teoria e Prática Pedagógica $(68 \mathrm{~h} / \mathrm{a})$, que desenvolve conteúdos de currículo, de organização do trabalho pedagógico e docente na Escola Básica, de planejamento de ensino e avaliação, etc.

As modificações introduzidas no currículo da Licenciatura em Artes Visuais, conforme os GRÁFICOS 3 e 4, ajudam a confirmar o que se vem afirmando. 


\section{GRÁFICO 3: Distribuição de Carga Horária no Currículo Licenciatura em Artes - Hab. Artes Visuais. CH Total: 2.310 h/a. Ano: 1999}

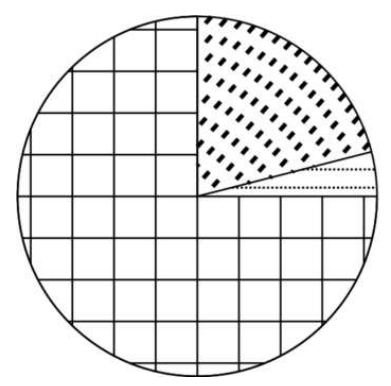

* Os Saberes Pedagógicos e as Ciências da Educação incluem as disciplinas: Psicologia da Educação I (60 h/a) e II (60 h/a); Filosofia da Educação I (60 h/a) e II (30 h/a); Fundamentos do Ensino da Arte (30 h/a); Fundamentos do Ensino da Arte II (30 h/a); Metodologia do Ensino I (60 h/a) e II (60 h/a); Estrutura e Funcionamento do Ensino (60 h/a).

Fonte: UFPel/PRG/DRA/SEÇÃO DE CURRÍCULOS E HISTÓRICOS. Curso: Licenciatura em Artes - Habilitação em Artes Visuais. 1999/1.

\section{GRÁFICO 4: Distribuição de Carga Horária no Currículo Curso de Artes Visuais -} Hab. Licenciatura. CH Total: 3.073 h/a. Ano: 2005

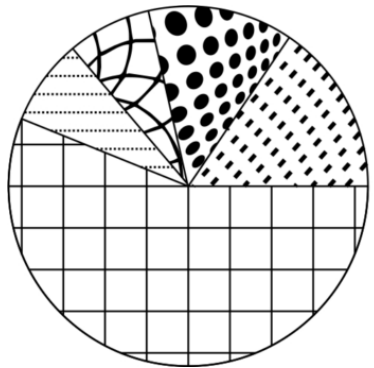

* Inclui as disciplinas: Teoria e Prática Pedagógica (68 h/a); Fundamentos Psicológicos da Educação (68 h/a); Fundamentos Sócio-Históricos-Filosóficos da Educação (68 h/a); Educação Brasileira (68 h/a).

* * Inclui as disciplinas: Artes Visuais na Educação I, II e III (204 h/a); Fundamentos do Ensino da Arte I e II (68 h/a); Projeto em Artes I e II (136 h/a).

Fonte: MEC/UFPel/ INSTITUTO DE LETRAS E ARTES/ COLEGIADO DO CURSO DE LICENCIATURA EM ARTES. Proposta de reformulação curricular e projeto pedagógico. Curso de Artes Visuais. Modalidade Licenciatura. Pelotas, out. 2005. 
Após a reforma curricular, a carga horária total do curso teve um acréscimo de 763 h/a, comparados os currículos de 1999 e de 2005. As horas acrescentadas foram distribuídas basicamente nos eixos da Prática como Componente Curricular - com 408 h/a, que incluem as Artes Visuais na Educação I, II e III (204 h/a), Fundamentos do Ensino da Arte I e II (68 h/a) e Projeto em Artes I e II (136 h/a) - correspondendo a 13\% da carga horária total; dos Estágios Supervisionados, com $459 \mathrm{~h} / \mathrm{a}$, correspondendo a $15 \%$; e das Atividades Complementares, com 200 horas, que representam 7\% do total do curso. As disciplinas de Projeto em Artes I e II, oriundas do currículo antigo, ocupam-se com a elaboração do Trabalho de Conclusão de Curso (TCC), que culmina com a elaboração de uma monografia que deve ser o resultado de uma pesquisa qualitativa sobre as artes visuais ou o ensino das artes visuais.

O eixo dos Saberes Pedagógicos e das Ciências da Educação, que antes contabilizava $450 \mathrm{~h} / \mathrm{a}$, com as disciplinas Psicologia da Educação I e II (120 h/a); Filosofia da Educação I e II (90 h/a); Fundamentos do Ensino da Arte I e II (60 h/a); Metodologia do Ensino I e II (120 h/a); Estrutura e Funcionamento do Ensino (60 h/a), correspondendo a 20\% do curso, após a reforma, sofreu uma brusca diminuição na carga horária, contando agora com apenas $272 \mathrm{~h} /$ a em quatro disciplinas da educação: Teoria e Prática Pedagógica (68 h/a); Fundamentos Psicológicos da Educação (68 h/a); Fundamentos Sócio-Históricos-Filosóficos da Educação (68 h/a); Educação Brasileira: Organização e Políticas Públicas $(68 \mathrm{~h} / \mathrm{a})$, totalizando $9 \%$ da carga horária total.

Destacam-se, justamente, esses componentes, já que, antes da reforma, os estágios ocupavam apenas 5\% da carga horária total, com 120 h/a, e os Saberes Pedagógicos e as Ciências da Educação correspondiam a $20 \%$, com $450 \mathrm{~h} /$ a distribuídas em nove disciplinas, enquanto, na atual configuração, o tempo destinado para os estágios aumentou em 15\%, e, para os Saberes Pedagógicos e as Ciências da Educação, diminuiu em 9\%, com quatro disciplinas. A diminuição na carga horária torna-se visível principalmente nas disciplinas de Psicologia da Educação I e II, de Filosofia da Educação I e II e de Metodologia do Ensino I e II, que tinham dois semestres para o estudo de cada uma, ficando reduzidas a apenas um semestre de Fundamentos Psicológicos; um de Fundamentos Sócio-Históricos-Filosóficos da Educação; e um de Teoria e Prática 
Pedagógica. As disciplinas de Fundamentos do Ensino da Arte I e II, pertencentes ao eixo dos Saberes Pedagógicos e das Ciências da Educação em 1999, foram realocadas no eixo da Prática como Componente Curricular em 2005, no qual também foram realocadas as disciplinas de Projeto em Artes I e II, que, antes, pertenciam ao eixo dos Conhecimentos Específicos da Área de Ensino. Esse último eixo, o dos Conhecimentos Específicos da Área de Ensino, não sofreu diminuição expressiva nas horas, pois passou de 1.740 para $1.734 \mathrm{~h} /$ a, porém, é notável que, com o grande acréscimo na carga horária total do curso, esse eixo tenha passado a corresponder apenas a 56\% a partir de 2005, o que evidencia que o aumento efetivo se deu pelo acréscimo no tempo de estágios e pela inclusão de PCC e das Atividades Complementares. Tal medida implicou a diminuição significativa de disciplinas relacionadas especialmente aos Saberes Pedagógicos de caráter humanista.

A distribuição do tempo entre os saberes curriculares no curso de Licenciatura em Matemática, em diferentes momentos históricos, dáse segundo pode ser observado nos GRÁFICOS 5 e 6.

\section{GRÁFICO 5: Distribuição de Carga Horária no Currículo Matemática - Licenciatura Plena. CH Total: 2.941 h/a. Ano: 2002}

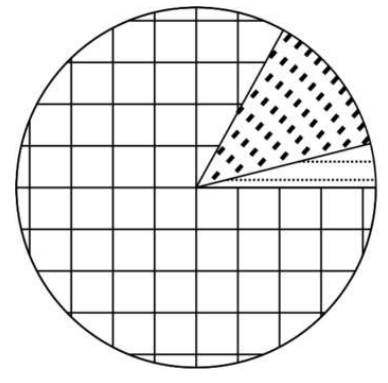

* Inclui as disciplinas: Filosofia da Educação (68 h/a); Estrutura e Funcionamento do Ensino I e II (136 h/a); Psicologia da Educação I e II (102 h/a); Didática Especial da Matemática I e II (136 h/a).

Fonte: MEC/UFPel/PRG/DEPARTAMENTO DE REGISTROS ACADÊMICOS. Currículo 1 - 3800 Matemática - Licenciatura Plena 2002/2. 


\section{GRÁFICO 6: Distribuição de Carga Horária no Currículo Matemática - Licenciatura Plena. CH Total: 3.430 h/a. Ano: 2005}

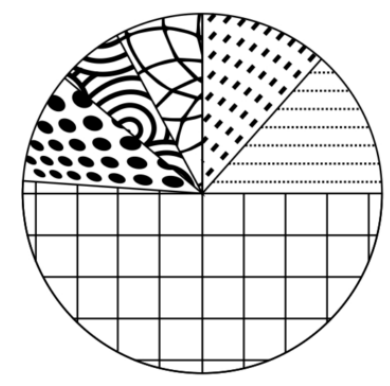

Saberes Pedagógicos e das Ciências da Educação 272 h/a* (8\%)

Prática como Componente Curricular $408 \mathrm{~h} / \mathrm{a}^{* *}(12 \%)$

Estágios Supervisionados $442 \mathrm{~h} / \mathrm{a}$ (13\%)

Conhecimentos Específicos da Área de Ensino 1768 h/a (51\%)

Disciplinas Optativas $340 \mathrm{~h} / \mathrm{a}$ (10\%)

Atividades Complementares $200 \mathrm{~h} / \mathrm{a}$ (6\%)

* Inclui as disciplinas: Teoria e Prática Pedagógica (68 h/a); Fundamentos Psicológicos da Educação (68 h/a); Fundamentos Sócio- Históricos-Filosóficos da Educação (68 h/a); Educação Brasileira (68 h/a); Libras I (68 h/a).

* Inclui as disciplinas: Laboratório de Ensino de Matemática I, II e III (cada um com 68 h/a); Instrumentação para 0 Ensino de Matemática I, II (cada um com 68 h/a) e Tecnologias Avançadas no Ensino de Matemática (68 h/a). Fonte: MEC/UFPel/IFM/CURSO DE LICENCIATURA EM MATEMÁTICA. Projeto pedagógico Licenciatura em Matemática, out. 2005.

O currículo da Licenciatura em Matemática, em funcionamento em 2005, teve um aumento de sua carga horária total em 489 h/a, considerando o modelo curricular vigente em 2002. As horas acrescentadas foram distribuídas basicamente em quatro eixos: Prática como Componente Curricular - $408 \mathrm{~h} / \mathrm{a}$ distribuídas entre as disciplinas de Laboratório de Ensino de Matemática I, II e III (cada uma com 68 h/a); Instrumentação para o Ensino de Matemática I e II (cada uma com 68 h/a) e Tecnologias Avançadas no Ensino de Matemática (68 h/a), correspondendo a $12 \%$ da carga horária total do curso; Estágio Supervisionado - $442 \mathrm{~h} /$ a distribuídas entre as disciplinas de Trabalhos de Campo I e II (cada uma com 85 h/a) e Estágio de Matemática I e II (cada uma com $136 \mathrm{~h} / \mathrm{a}$ ), correspondendo a 13\% da carga horária total; Atividades Complementares, com 200 horas, o que corresponde a 6\%; e Disciplinas Optativas, compostas por disciplinas de formação científica do professor na sua área de ensino e de formação pedagógica, totalizando $10 \%$ da carga horária total do curso.

Considerando-se que as didáticas, na maior parte das vezes, passaram a compor a carga horária das PCC, houve um decréscimo no tempo destinado ao estudo dos saberes pedagógicos de caráter mais humanista. No primeiro gráfico, observa-se que Filosofia da Educação, 
Estrutura e Funcionamento do Ensino I e II e Psicologia da Educação I e II tinham em conjunto $306 \mathrm{~h} / \mathrm{a}$, passando, no currículo de 2005, a ocupar $272 \mathrm{~h} / \mathrm{a}$ da carga horária, distribuída entre as disciplinas de Teoria e Prática Pedagógica (68 h/a), Fundamentos Psicológicos da Educação (68 h/a), Fundamentos Sócio-Históricos-Filosóficos da Educação (68 h/a), Educação Brasileira: Organização e Políticas Públicas $(68 \mathrm{~h} / \mathrm{a})$ e LIBRAS I (68 h/a), reduzindo o percentual de 13\% para $8 \%$.

As disciplinas de Didática Especial da Matemática I e II, anteriormente alocadas no eixo dos Saberes Pedagógicos e das Ciências da Educação, computando $136 \mathrm{~h} / \mathrm{a}$, após a reforma, foram renomeadas e realocadas, junto a outras disciplinas, no eixo de Prática como Componente Curricular, acrescendo em 276 h/a a carga horária.

Também as disciplinas de formação científica do professor na sua área de ensino sofreram um rebaixamento em termos de carga horária, passando de 2.431 h/a em 2002 para 1.768 h/a em 2005, o que, em termos percentuais, representa um decréscimo de $83 \%$ para $51 \%$, embora com o aumento significativo na carga horária total do curso.

Isso evidencia, como no PPP de outros cursos, que o aumento efetivo de carga horária do Curso de Licenciatura em Matemática se deu em função dos eixos de PCC, Estágios e Atividades Complementares, cuja inclusão forçou também a diminuição significativa de disciplinas relacionadas à formação científica do professor na sua área de ensino e aos Saberes Pedagógicos e Ciências da Educação. 


\section{GRÁFICO 7: Distribuição de Carga Horária no Currículo Ciências Sociais Hab. Licenciatura. CH Total: 2.856 h/a. Ano: 1998}

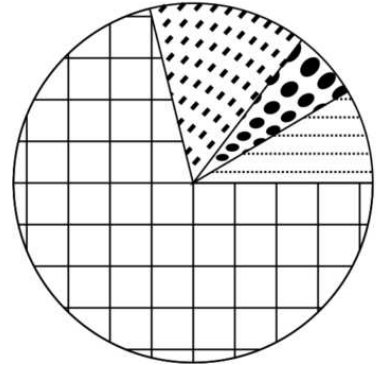

* Inclui as disciplinas: Teoria e Prática Pedagógica (68 h/a); Fundamentos Psicológicos da Educação (68 h/a); Fundamentos Sócio- Históricos-Filosóficos da Educação (68 h/a); Educação Brasileira (68 h/a); Libras I (68 h/a).

** Inclui as disciplinas: Prática em Ciências Sociais I, II, III, IV e V.

Fonte: MEC/UFPel/PRG/DEPARTAMENTO DE REGISTROS ACADÊMICOS. Currículo 1- 3220. Ciências Sociais - Hab. Licenciatura. 1998/1.

\section{GRÁFICO 8: Distribuição de Carga Horária no Currículo Ciências Sociais Hab. Licenciatura. CH Total: 2.618 h/a. Ano: 2004}

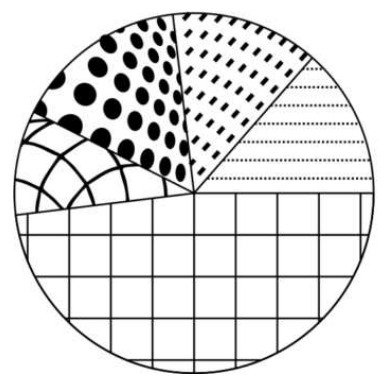

* Inclui as disciplinas: Teoria e Prática Pedagógica (68 h/a); Fundamentos Psicológicos da Educação (68 h/a); Fundamentos Sócio- Históricos-Filosóficos da Educação (68 h/a); Educação Brasileira (68h/a); Libras I (68 h/a).

** Inclui as disciplinas: Prática em Ciências Sociais I, II, III, IV e V.

Fonte: MEC/UFPel/PRG/DEPARTAMENTO DE REGISTROS ACADÊMICOS. Currículo. Ciências Sociais - Habilitação Licenciatura - 2004/1.

O currículo reformado dessa licenciatura é o único do estudo que teve diminuída a carga horária total $(2.618 \mathrm{~h} / \mathrm{a})$, considerando o currículo vigente em 1998 ( 2.856 h/a), que fornecia as duas habilitações, o bacharelado e a licenciatura. Houve uma redução de 238 h/a na carga horária total do curso e, ainda, uma impressionante perda de 761 h/a do 
tempo destinado ao estudo dos conhecimentos que são objeto de ensino do futuro professor. Esse conjunto de conhecimentos ocupava aproximadamente $71 \%$ do currículo de 1998 e passa a ocupar em torno de $48 \%$ no currículo de 2004, redução que se explica pela exigência legal de contemplar a carga horária estipulada para a Prática como Componente Curricular, para o Estágio Curricular Supervisionado e as Atividades Complementares. O aumento da carga horária dos cursos em virtude da implantação da matriz curricular oficial provocou embates e problemas especialmente nos cursos noturnos, que, tendo que fazer uma oferta concentrada de créditos em um único turno, não poderia expandir em muito sua carga horária total sem, ao mesmo tempo, expandir a duração do curso em anos, passando de quatro para cinco anos. A licenciatura com oferta no turno da noite aqui estudada preferiu manter sua duração nos quatro anos, tendo, assim, que excluir conhecimentos das disciplinas do campo das Ciências Sociais e dos Fundamentos da Educação.

Assim como os demais, o currículo desse curso de licenciatura incluiu um aumento significativo do tempo dedicado ao estágio. No currículo de 1998, com a denominação de Prática de Ensino de $2^{\circ}$ Grau, ocupava um único semestre, com $170 \mathrm{~h} / \mathrm{a}$, passando, no currículo de 2004, a compor três semestres de estágio em Ciências Sociais, totalizando $408 \mathrm{~h} / \mathrm{a}$, portanto, mais que o dobro do tempo dedicado a essa atividade, no currículo de 1998.

Para atender a exigência legal de 400 horas de Prática como Componente Curricular, o curso organizou cinco semestres de Prática em Ciências Sociais, com um total de 408 h/a, componente que já estava presente no modelo curricular de 1998, com um número bem inferior de horas $(221 \mathrm{~h} / \mathrm{a})$.

Considerando que os conteúdos das disciplinas de Didática I e Didática II, que faziam parte do currículo de 1998, passaram, no currículo de 2004, a fazer parte das disciplinas de Prática em Ciências Sociais, as $374 \mathrm{~h} / \mathrm{a}$ previstas para o conjunto das disciplinas de Filosofia da Educação; Sociologia: Educação, Escola e Sociedade; Psicologia da Educação; Estrutura e Funcionamento do Ensino, do currículo de 1998, foram reduzidas para $272 \mathrm{~h}$ /a, no currículo de 2004, não incluindo a disciplina de LIBRAS. Portanto, houve uma redução de aproximadamente $100 \mathrm{~h} / \mathrm{a}$ no currículo para o estudo de conhecimentos educacionais e pedagógicos relacionados às ciências básicas da educação. 
Pelo conjunto dos gráficos, pode-se observar que, em relação aos currículos do período anterior à reforma, ocorre, em três dos casos estudados, um aumento significativo da carga horária total dos cursos, por força da inclusão das 400 horas de Prática como Componente Curricular, das 400 horas de Estágio e das 200 horas de Atividades Complementares. No caso da Licenciatura em Ciências Sociais, o único curso noturno da amostra, a opção para incluir as determinações oficiais, mantendo a duração de quatro anos do curso, foi realizar cortes especialmente nos conhecimentos específicos da área de ensino da licenciatura. Há, sem dúvida, em todos os currículos, um ganho de tempo para os estudos de natureza educacional e didático-pedagógica. No entanto, o aumento desse tempo foi concomitante à redução do tempo dedicado aos estudos relacionados às ciências básicas da educação e de caráter pedagógico humanístico, que permitem o desenvolvimento da reflexão madura e da criatividade intelectual. Esses conhecimentos representam, nos novos currículos, uma média de 9,5\% da carga horária total dos cursos. Enquanto os componentes de ordem prática assumem um valor de campo de saber ou de conhecimento e destacamse nos currículos dos cursos analisados, correspondendo à média de $26 \%$ da carga horária total deles.

\section{Considerações finais}

Como discutido, as diretrizes curriculares nacionais tiveram na prática o fundamento da competência docente e uma instância privilegiada de aprendizagem da docência, com base em um referencial de cunho prático-reflexivo. Desse modo, entende-se que a prática e os saberes de ordem prática, no processo de formação, atuam como uma tecnologia do eu docente, no interior da qual os aspirantes à licença exercem um trabalho sobre si com a intenção de assegurarem ou construírem suas identidades profissionais e seus modos de ser e agir no mundo e com os outros.

Entende-se que as diretrizes apontam para um autogoverno da conduta do futuro docente em formação, que transfere para o indivíduo a responsabilização por sua formação e carreira profissional. A prática, tais como outras experiências de conhecimento, atuam como tecnologias do eu, definidas por Foucault como um conjunto de discursos, de 
saberes e práticas através das quais os indivíduos estabelecem uma relação consigo mesmos e

[...] que permitem aos indivíduos efetuar, por conta própria ou com a ajuda de outros, certo número de operações sobre seu corpo e sua alma, pensamentos, conduta, ou qualquer forma de ser, obtendo assim uma transformação de si mesmos com o fim de alcançar certo estado de felicidade, pureza, sabedoria (FOUCAULT, 1990c, p.48).

A ideia central aqui defendida é a de que o aumento da carga horária dos estágios e a inserção do elemento de Prática como Componente Curricular, os quais totalizam, no mínimo, 800 horas, direcionam para uma intensificação da autoformação docente, calcada em uma teoria pragmática de reflexão e autorreflexão. Pode-se, assim, entender a prática como um modo de subjetivação do futuro professor, tendo como elemento dinamizador principal a elaboração ou reelaboração da ação reflexiva consigo mesmo.

Segundo Larrosa (1994, p.49), o professor reflexivo é aquele "capaz de examinar e reexaminar, regular e modificar constantemente tanto sua própria atividade prática quanto, sobretudo, a si mesmo". O futuro professor define e elabora sua identidade, quando oferece a si mesmo momentos de observação, decifração, descrição, julgamento, narração e domínio de si. A noção de experiência de si é o resultado de um entrecruzamento de discursos de verdade que definem o sujeito, as práticas que o regulam e as formas de subjetividade nas quais ele se constitui. Nesse processo, o indivíduo é levado a examinar e reexaminar, regular e modificar constantemente sua prática e a si mesmo.

O aumento da carga horária de prática tem como efeito, do ponto de vista da política oficial, o desenvolvimento de um conhecimento tácito mais completo e abrangente, de forma a proporcionar aos acadêmicos um domínio da ação docente e de si mesmos, com a expectativa de que é através da prática que os professores conhecem realmente os problemas da educação brasileira. Como dizem Dias e Lopes (2009, p.87): "Essa perspectiva tende a certo enfoque empirista por valorizar como base do conhecimento 'verdadeiro' o que é apreendido, exclusivamente, pela experiência".

É claro que todo o curso de formação profissional demanda sempre a aprendizagem de habilidades, conhecimentos e saberes em 
situações que procuram ser simétricas às que o futuro professor irá experimentar em contextos laborais já no exercício da profissão. A experiência tem efetivamente um papel central na construção da competência docente, e situações em que os alunos, futuros professores, são levados a essas vivências, fazem e devem fazer parte da socialização profissional desses sujeitos. No entanto, os modos como essa questão é tratada na legislação e nos currículos reformados acentuam formas de profissionalismo baseadas em uma racionalidade prática e instrumental, que fez, e continua fazendo, história no campo educacional e pedagógico.

O termo prática no imaginário pedagógico e educacional remete a uma perspectiva filosófica pragmatista, marca da pedagogia moderna e da modernidade pedagógica no Brasil, na primeira metade do século XX. A normalização dos professores e da ação docente no interior de registros que privilegiam os saberes da prática e que tratam o ensino como um problema de "saber-fazer" ou de "saber fazendo" as escolhas instrucionais adequadas tem sua genealogia na história da constituição do magistério, ainda ao longo do século XIX e início do século XX, como um trabalho de autodidatas talentosos e artesãos que faziam de sua atuação no ensino uma obra de arte e de vida.

Loureiro (2007), fazendo uma crítica à influência do pragmatismo na educação moderna, salienta a vigência de uma certa "aversão" pela teoria, que implica uma "indigência" da prática no campo educacional. Pode-se fazer uma analogia pensando a política oficial para a formação inicial de professores. Essa característica despotencializa a abstração e a invenção discursiva sobre os fenômenos da escolarização, da pedagogia e do ensino, reinscrevendo a tarefa pastoral dos professores como especialistas no manejo de procedimentos e estratégias mais eficazes de moralização e disciplinamento dos corpos e das consciências de seus estudantes (GARCIA, 2002; POPKEWITZ, 2001).

Mas, por outros pontos de vista, a assimilação dos termos prática e experiência não é tranquila. Argumentando a favor de uma distinção entre prática e experiência, Larrosa (2002a, b) diz que a experiência remete ao que nos passa, ao que nos afeta e transforma, e não simplesmente aquilo que passa ou vivemos. A experiência implica a modificação de quem somos, nossa transformação naquilo que não éramos a princípio. Portanto, a relação com o conhecimento ou com o que fazemos não é necessariamente uma experiência em um sentido restrito, 
pois nem sempre somos formados ou transformados pelo conhecimento ou por nossas ações. Cancelar as fronteiras entre o que sabemos, ou o que fazemos, e o que somos, é um desafio enorme (LARROSA, 2002a).

Os alunos, nos cursos de formação docente, não são simplesmente indivíduos que têm experiências em contato com as escolas, realizando observações ou assumindo a docência em uma sala de aula. Eles são constituídos no interior dessas experiências que são fundamentalmente discursivas, sendo, portanto, também atravessados pela rotina, pela burocracia, pela tradição, pelo conservadorismo, etc. Ser capaz de avaliá-las criticamente e analisá-las de modo mais complexo exige aportes teóricos e conceituais que não deveriam ser minimizados no processo de formação inicial dos professores.

Assim, conclui-se com alguma coisa que parece um tanto óbvia, mas que, com seu canto e seus encantos, continua seduzindo e cativando os ânimos por uma formação de qualidade para as professoras da Educação Básica. Pelo contexto investigado, pode-se afirmar que acrescentar mais prática aos currículos da formação inicial das docentes não implica necessariamente um acréscimo de sabedoria e de qualidade na formação inicial. A prática, tal como vem sendo predominantemente tratada pelos cursos, refunda a dicotomia entre teoria e prática e uma forma de pragmatismo que enfraquece versões mais complexas de profissionalismo docente. 


\section{NOTAS}

\section{Apoio CNPQ.}

2 A relação teoria e prática em todas as suas manifestações nos currículos de formação de professores ainda é tema pouco explorado na literatura especializada em formação de professores. Dois levantamentos indicam isso: VIEIRA, N. F.; GARCIA, M. M. A. (2012), tendo como fonte as revistas especializadas da área educacional classificadas pelo Qualis/Capes de 2012 em A1 e A2, publicado em março de 2012, no período de 2000-2011, indicando que, de 361 referências levantadas com os descritores Formação de Professores e Formação Docente, somente 23 tiveram como tema a relação teoria e prática na formação inicial dos professores ou faziam referência a termos relacionados a essa questão: prática, epistemologia da prática, teoria e prática, relação teoria e prática, saberes docentes. Assim como também os temas da prática de ensino e/ou do estágio na formação inicial dos docentes parecem não atrair os pesquisadores do campo. Confira o estudo de LEITE, V. C.; GARCIA, M. M., 2012.

3 Os outros conhecimentos que participam do desenvolvimento profissional dos professores, além do conhecimento que advém da experiência, são: cultura geral e profissional; conhecimento sobre crianças, jovens e adultos; conhecimento sobre a dimensão cultural, social, política e econômica da educação; conteúdos das áreas de conhecimento que são objeto de ensino; conhecimento pedagógico (BRASIL, 2001a).

4 Serão utilizadas versões com datas diferenciadas dos currículos dos cursos investigados em virtude da impossibilidade de acesso a versões com as mesmas datas. A opção foi garantir que a comparação se desenvolvesse entre uma versão do currículo do curso vigente anteriormente à reforma e uma versão do currículo já reformado.

\section{REFERÊNCIAS}

BALL, S. What is policy? Texts, trajectories and toolboxes. In: Education reform: a critical and post-structural approach. Buckingham / Philadelphia: Open University Press, 1994. p.14-27.

BALL, S. Profissionalismo, gerencialismo e performatividade. Cadernos de Pesquisa, São Paulo, v.35, n.126, p.539-564, set./dez. 2005.

BERNSTEIN, B. Pedagogia, control simbólico e identidad. Madrid: Morata, 1998.

BRASIL. Conselho Nacional de Educação. Parecer CNE/CP 9/2001, de 8 de maio de 2001a. Diretrizes Curriculares Nacionais para a Formação de Professores da Educação Básica, em nível superior, curso de licenciatura, de graduação plena. Publicado no Diário Oficial da União, Brasília, DF, 18 de jan. 2002. seção 1. p.31. Disponível em: http://portal.mec.gov.br/cne/arquivos/pdf/009.pdf. Acesso em: 3 mar. 2004.

BRASIL. Conselho Nacional de Educação. Parecer CNE/CP 21/2001, de 6 de agosto de 2001b. Não homologado por ter sido retificado pelo Parecer CNE/CP 28/2001. Duração e carga horária dos cursos de Formação de Professores da Educação Básica, 
em nível superior, curso de licenciatura, de graduação plena.

BRASIL. Conselho Nacional de Educação. Parecer CNE/CP 28/2001, de 2 de outubro de 2001c. Dá nova redação ao Parecer CNE/CP 21/2001, que estabelece a duração e a carga horária dos cursos de Formação de Professores da Educação Básica, em nível superior, curso de licenciatura, de graduação plena. Publicado no Diário Oficial da União de 18/01/2002, Seção 1, p.31.

BRASIL. Conselho Nacional de Educação. Resolução CNE/CP 1/2002, de 18 de fevereiro de 2002a. Institui Diretrizes Curriculares Nacionais para a Formação de Professores da Educação Básica, em nível superior, curso de licenciatura, de graduação plena. Disponível em: http://portal.mec.gov.br/cne/arquivos/pdf/rcp01_02.pdf. Acesso em: 3 mar. 2004

BRASIL. Conselho Nacional de Educação. Resolução CNE/CP 2/2002, de 19 de fevereiro de 2002b. Diário Oficial da União, Brasília, DF, 4 de mar de 2002, seção 1, p.9. Institui a duração e a carga horária dos cursos de licenciatura, de graduação plena, de Formação de Professores da Educação Básica em nível superior. Disponível em: http://portal.mec.gov.br/cne/arquivos/pdf/CP022002.pdf. Acesso em: 3 mar. 2004.

DIAS, R. E.; LOPES, A. C. Sentidos da prática nas políticas de currículo para a formação de professores. Currículo sem Fronteiras, v.9, n.2, p.79-99, jul./dez. 2009. Disponível em: <http://www.curriculosemfronteiras.org/art_v9_n2.htm>. Acesso em: 30 Janeiro de 2010.

DUARTE, N. Conhecimento tácito e conhecimento escolar na formação do professor (por que Donald Schön não entendeu Luria). Educ. Soc., Campinas, v.24, n.83, p.601625, ago. 2003.

FOUCAULT, M. Verdade e poder. In: . Microfísica do poder. 9.ed. Rio de Janeiro: Graal, 1990a. p.1-14.

FOUCAULT, M. A governamentalidade. In: Mícrofísica do poder. 9ed. Rio de Janeiro: Graal, 1990b. p.179-191.

FOUCAULT, M. Tecnologías del yo. In: Tecnologías del yo y otros textos afines. Introducción de Miguel Morey. Barcelona: Paidós Ibérica / I.C.E. de la Universidad Autónoma de Barcelona, 1990c. p.45-94.

FOUCAULT, M. A arqueologia do saber. 4.ed. Rio de Janeiro: Forense Universitária, 1995.

FREITAS, H. Formação de professores no Brasil: 10 anos de embate entre projetos de formação. Educ. Soc., Campinas, v.23, n.80, p.136-16, set. 2002.

GARCIA, M. M. A. Pedagogias críticas e subjetivação: uma perspectiva foucaultiana. Petrópolis: Vozes, 2002.

GARCIA, M. M. Didática e trabalho ético na formação docente. Educação e Pesquisa, São Paulo, v.39, n.136, p.225-242, 2009.

GAUTHIER, C. Por uma teoria da pedagogia: pesquisas contemporâneas sobre o saber docente. Ijuí: Editora da UNIJUÍ, 1998.

LARROSA, J. Tecnologias do eu e educação. In: SILVA, T. T. da. O sujeito da educação: estudos foucaultianos. Petrópolis: Vozes, 1994. p.35-86.

LARROSA, J. Notas sobre a experiência e o saber de experiência. RBE, Rio de Janeiro, n.19, p.20-28, jan./fev./abr. 2002a.

LARROSA, J. Literatura, experiência e formação. In: COSTA, M. V. (Org.). Caminhos 
investigativos: novos olhares da pesquisa em educação. 2.ed. Rio de Janeiro: DP\&A, 2002b. p.133-160.

LEITE, V. C. L.; GARCIA, M. M. A. Investigação sobre o estágio na formação docente através do levantamento de pesquisas no período 2000-2011. In: ENPÓS Encontro de Pós-Graduação, 14., Pelotas. Anais... Pelotas, Universidade Federal de Pelotas (UFPel), 2012. (CD-ROM).

LOUREIRO, R. Aversão à teoria e indigência da prática: crítica a partir da filosofia de Adorno. Educ. Soc., Campinas, v.28, n.99, p.522-541, maio/ago. 2007.

MEC/UFPel/ESEF/COLEGIADO DE CURSO. Projeto pedagógico do curso de Licenciatura em Educação Física. Pelotas, abril de 2009.

MEC/UFPel/PRG/DRA/SEÇÃO DE CURRÍCULOS E HISTÓRICOS. Curso: Licenciatura em Artes - Habilitação em Artes Visuais. 1999/1.

MEC/UFPel/ INSTITUTO DE LETRAS E ARTES/ COLEGIADO DO CURSO DE LICENCIATURA EM ARTES. Proposta de reformulação curricular e projeto pedagógico. Curso de Artes Visuais. Modalidade Licenciatura. Pelotas, out. 2005.

MEC/UFPel/PRG/DEPARTAMENTO DE REGISTROS ACADÊMICOS. Currículo 1 - 3800. Matemática - Licenciatura Plena 2002/2.

MEC/UFPel/IFM/CURSO DE LICENCIATURA EM MATEMÁTICA. Projeto pedagógico Licenciatura em Matemática. Out. 2005.

MEC/UFPel/PRG/DEPARTAMENTO DE REGISTROS ACADÊMICOS. Currículo 1- 3220. Ciências Sociais - Hab. Licenciatura. 1998/1.

MEC/UFPel/PRG/DEPARTAMENTO DE REGISTROS ACADÊMICOS. Currículo. Ciências Sociais - Habilitação Licenciatura - 2004/.

NÓVOA, A. Formação de professores e formação docente. In: (Org.). Os professores e a sua formação. 3.ed. Lisboa: Dom Quixote, Instituto de Inovação Educacional, 1997. p.15-34.

PERRENOUD, P. Práticas pedagógicas, profissão docente e formação: perspectivas sociológicas. Lisboa: Dom Quixote, 1993.

PIMENTA, S. G. Saberes pedagógicos e atividade docente. São Paulo: Cortez, 1998.

POPKEWITZ, T. S. Reforma educacional; uma política sociológica: poder e conhecimento em educação. Porto Alegre: ARTMED, 1997

POPKEWITZ, T. S. Lutando em defesa da alma: a política do ensino e a construção do professor. Porto Alegre: ARTMED, 2001.

SCHÖN, D. Formar professores como profissionais reflexivos. In: NÓVOA, A. (Org.). Os professores e a sua formação. 3.ed. Lisboa: Dom Quixote, Instituto de Inovação Educacional, 1997. p.79-91.

SCHÖN, D. Educando o profissional reflexivo: um novo design para o ensino e a aprendizagem. Porto Alegre: Artmed, 2000.

TARDIF, M. Saberes docentes e formação profissional. 5.ed. Petrópolis/RJ: Vozes, 2002. UNIVERSIDADE FEDERAL DE PELOTAS/ PRÓ-REITORIA DE GRADUAÇÃO/ DEPARTAMENTO DE REGISTROS ACADÊMICOS. Currículo 1 - 800 Educação Física - Lic. Plena - 2001/2. Pelotas. Impresso em 17/08/2006.

VIEIRA, N. F.; GARCIA, M. M. A. A produção acadêmica sobre formação docente e relação teoria e prática: resultados parciais de um estudo do tipo "Estado do Conhecimento" (2000-2011). In: CIC - Congresso de Iniciação Científica/ $4^{a}$ Mostra 
Científica, 21., Pelotas. Anais... Pelotas, Universidade Federal de Pelotas (UFPel), 2012. (CD-ROM).

ZEICHNER, K. M. A formação reflexiva de professores: ideias e práticas. Lisboa: Educa, 1993.

ZEICHNER, K. M. Novos caminhos para o practicum: uma perspectiva para os anos 90. In: NÓVOA, A. (Org.). Os professores e a sua formação. 3.ed. Lisboa: Dom Quixote, Instituto de Inovação Educacional, 1997. p.115-138.

Recebido: $13 / 09 / 2012$

Aprovado: 08/07/2013

Contato:

Departamento de Ensino

Faculdade de Educação

Universidade Federal de Pelotas

Rua Gomes Carneiro, 1

Centro

CEP 96010-610

Pelotas | RS | Brasil 